\title{
Distinction Between Dry and Raw Milk Using Monoclonal Antibodies Prepared Against Dry Milk Proteins
}

\author{
W. L. Chen, M. T. Huang, H. C. Liu, C. W. Li, and S. J. T. Mao \\ Department of Biological Science and Technology, \\ National Chiao Tung University, Hsinchu, \\ Taiwan, Republic of China
}

\section{ABSTRACT}

It is well established that the heating process during the preparation of dry milk (DMLK) causes structural changes in some milk proteins. However, because such changes are subtle, whether they can be detected by an immunochemical approach remains questionable. The present study attempted to develop a sensitive $\mathrm{mAb}$ that might distinguish the DMLK from freshly prepared raw milk. To test this possibility, we immunized mice with commercially prepared DMLK and produced a panel of mAb. From 900 hybridomas screened using an ELISA, 4 clones were found to be specific to DMLK; the other 68 clones recognized both DMLK and raw milk. In contrast to polyclonal antibodies, only the specific mAb could detect the DMLK spiked into the raw milk at as low as $5 \%$ in concentration ( $\mathrm{vol} / \mathrm{vol}$ ). Western blot analysis shows that these specific $\mathrm{mAb}$ were all directed against $\beta$-lactoglobulin (LG) and LG-milk protein conjugates. These mAb reacted with raw milk heated at $95^{\circ}$ for $15 \mathrm{~min}$; the reaction with LG-conjugates, however, was abolished when treated with reducing reagent. Thus, results suggests that a new antigenic epitope was exposed in a heating process, and the thio group of LG cross linked with other protein moiety played a provocative role in $\mathrm{mAb}$ recognition. A hypothetical model with respect to the interaction between the mAb and DMLK is proposed and discussed.

(Key words: monoclonal antibody, dry milk, $\beta$-lactoglobulin, thermal denaturation)

\section{Abbreviation key: DMLK = dry milk.}

\section{INTRODUCTION}

Dairy industries are interested in knowing the appropriate heat treatment of milk to control drinking

Received November 23, 2003.

Accepted January 20, 2004.

Corresponding author: S. J. T. Mao; e-mail: mao1010@ms7. hinet.net. milk quality and to control the heating system. Consumers are concerned whether dry milk (powdered milk; DMLK) has been supplemented to pasteurized raw milk. Particularly, such supplementation happens when the supply of raw milk is not sufficient in the summer as consumer demand increases and cow milk production decreases. Because the ultra-heat treatment procedure has been widely used in preparing milk powder, efforts using heat-denatured milk proteins as bioindicators have been extended to detect false practices (Relkin, 1996; Sanchez et al., 2002; Steffensen et al., 2002). For example, Recio and Olieman (1996) showed that the amount of heat-denatured proteins could be estimated by analyzing the casein fraction using capillary zone electrophoresis. A fluorescent probe with an intrinsic analysis has suggested that the stability of proteins in aqueous solution is a function of temperature (Tsonev and Hirsh, 2000). Monoclonal antibody prepared against $\beta$-LG has been used to study the biological properties of LG, such as its interaction with ligands and hypersensitivity reactions (Venien et al., 1997; Clement et al., 2002; Selo et al., 2002; Kobayashi et al., 2001; Restani et al., 1999; Morgan et al., 1999). Nevertheless, there are no immunochemical methods presently used to detect DMLK mixed in raw milk.

The purpose of the present report was to use DMLK as an antigen to randomly produce a panel of $\mathrm{mAb}$ and then select the monoclonals (if any) that were able to discriminate between the DMLK and raw milk. Using an ELISA, we established that 4 monoclonals possessed such a unique property. Further characterization revealed that these $\mathrm{mAb}$ were directed toward LG epitope on a Western blot analysis. Simultaneouly, we also demonstrated that the specificity achieved in these DMLK antibodies was due to, in part, the crosslinking of LG with the other milk proteins. A hypothetical model explaining their specificity is described in details.

\section{MATERIALS AND METHODS}

\section{Preparation of Milk Samples}

Bulked whole raw milk obtained from a university dairy farm (Tunghi University, Taichung, Taiwan) 
and DMLK (Nestle Australia Ltd, Sidney, Australia) without further heat or other manipulation (unless specifically mentioned) were used for PAGE, Western blot, and ELISA analyses.

\section{Animal Care and Use}

The mAb productions were used on Balb/c mice that were 5 to $7 \mathrm{wk}$ of age (National Science Council of Taiwan). The mice were fed in an animal room at Chiao Tung University during the period of immunization. Feed and water were available daily. Carbon dioxide gassing was used as the method of sacrificing, and the other management was conducted according to guidelines established by the National Science Council of Taiwan.

\section{Immunization of Mice}

Female Balb/c mice (5 to 7 wk of age) were used for immunization according to the method previously described (Yang and Mao, 1999). In brief, DMLK protein in sterilized PBS, containing $0.12 \mathrm{M} \mathrm{NaCl}$ and $0.02 M$ phosphate ( $\mathrm{pH} 7.4$ ), was mixed and homogenized with an equal volume of incomplete Freund's adjuvant by a three-way stopcock. Each mouse was initially given a total emulsion of $0.5 \mathrm{~mL}$ containing $200 \mu \mathrm{g}$ of protein with 6 s.c. injections onto the back and an i.p. injection. At d 7, an identical dose with incomplete adjuvant was given intraperitoneally followed by 2 i.m. injections without adjuvant at $\mathrm{d} 14$. Seven days following a final booster, blood was collected in $0.1 \%$ (wt/vol) EDTA, and plasma was obtained. This plasma was used as a source for conventional polyclonal antibody against DMLK. The titers of this antibody were over 1:8000 as judged by an ELISA previously established in our laboratory (Huang et al., 1999). The spleen obtained was used to prepare hybridoma fusion.

\section{Production of mAb}

Monoclonal antibodies were produced according to the standard procedures previously described (Mao et al., 1988; Mao et al., 1990). In brief, myeloma cell line (FO) was fused with spleen cells from immunized Balb/ $\mathrm{c}$ mice at a ratio of 1:5. Fusion was carried out within $2 \mathrm{~min}$ at $37^{\circ} \mathrm{C}$ using $1 \mathrm{~mL}$ of $50 \%$ (wt/vol) polyethylene glycol containing 10\% (vol/vol) DMSO (Hybri-Max; Sigma). Cell mixture was then washed and resuspended in HAT medium (Hybri-Max) containing approximately $1 \times 10^{5} \mathrm{FO}$ cells $/ \mathrm{mL}$. The suspended cells were distributed as $100 \mu \mathrm{L}$ per well in 96-well microtiter plates and incubated at $37^{\circ} \mathrm{C}$ in a $5 \% \mathrm{CO}_{2}$-incubator followed by an addition of $100 \mu \mathrm{L}$ of fresh HAT medium after $7 \mathrm{~d}$. Subsequently, culture medium was assayed for the production of specific antibodies, between 14 and $21 \mathrm{~d}$ following the fusion, using a solid-phase ELISA described subsequently. After primary screening, desired hybridomas were selected, expanded, and subcloned. Each monoclonal was established by limiting dilutions at least $2 \times$ (Mao et al., 1988, 1990).

\section{ELISA}

Initially, approximately $1 \mu \mathrm{g}$ of DMLK or raw milk protein in $50 \mu \mathrm{L}$ of PBS was coated on each well of an ELISA plate (Nunc, Roskilde, Denmark) for screening hybridoma antibodies. Unbound proteins were washed with PBS $3 \times$ and subsequently blocked by an addition of $350 \mu \mathrm{L}$ of $1 \%$ (wt/vol) gelatin for $30 \mathrm{~min}$ (Mao et al., 1988). Following washes with PBS, $50 \mu \mathrm{L}$ of hybridoma culture medium (2 to $3 \mathrm{wk}$ following the fusion) were added and incubated at room temperature for 60 to 90 min. Each well was washed $3 \times$ with PBS containing $0.1 \%$ gelatin and $0.05 \%$ Tween-20. Bound antibodies were detected using a goat anti-mouse IgG conjugated with horseradish peroxidase for $30 \mathrm{~min}$ in PBS containing $0.1 \%$ gelatin and $0.05 \%$ Tween-20. Finally, each well was washed and developed with $0.04 \%$ (wt/ vol) 2,2-Azino-bis(3-ethylbenz-thiazoline-6-sulfonic acid) (ABTS) containing $0.01 \%$ (vol/vol) $\mathrm{H}_{2} \mathrm{O}_{2}$ in PBS.

\section{Gel Electrophoresis}

Sodium dodecyl sulfate-PAGE or native PAGE containing $15 \%$ (wt/vol) polyacrylamide (unless specified) was used to characterize the milk proteins using a modified procedure (Yang and Mao, 1999) similar to that described by Oldfield et al. (1998). Electrophoresis was conducted in a vertical slab gel unit (Mini PIII, Bio-Rad) equipped with a PAC 300 power supply (BioRad). All samples (5 to $20 \mu \mathrm{g}$ ) for SDS-PAGE were equilibrated in $10 \mathrm{mM}$ Tris-HCl and 5\% SDS (pH 7.6) before loading to the gel. It is worthy to mention that preheat treatment used in the conventional SDSPAGE for the tested samples was omitted to ensure the native structure of unheated milk proteins. The same procedures were conducted for native PAGE without the addition of SDS.

\section{Western Blot Analysis}

Following SDS-PAGE or native PAGE, the gel was soaked briefly and instantly in a transfer buffer containing $25 \mathrm{~m} M$ Tris, $192 \mathrm{~m} M$ glycine, $20 \%$ methanol, and $0.0375 \%$ SDS ( $\mathrm{pH} 8.3$ ) for $30 \mathrm{~s}$. The gel was then immediately electrotransferred to a nitrocellulose 
Table 1. Designated monoclonal antibodies specific to dry milk (DMLK) and their characterizations.

\begin{tabular}{|c|c|c|c|c|}
\hline & \multirow[b]{2}{*}{ Hybridoma } & \multicolumn{2}{|c|}{ ELISA specific to } & \multirow[b]{2}{*}{ IgG subclass } \\
\hline & & $\begin{array}{l}\text { Raw milk } \\
\text { and DMLK }\end{array}$ & DMLK & \\
\hline \multirow{6}{*}{$\begin{array}{l}\text { Primary hybridoma, no. } \\
\text { Established and } \\
\text { expanded monoclonals } \\
\text { mAb designated }\end{array}$} & 900 & 68 & 8 & \\
\hline & & 20 selected & 4 & \\
\hline & & & DM 1 (1B5F2) & IgG1 \\
\hline & & & DM 2 (1D8F8) & IgG1 \\
\hline & & & DM 3 (2F2D9) & IgG1 \\
\hline & & & DM 4 (2B3D11) & IgG1 \\
\hline \multirow{2}{*}{\multicolumn{2}{|c|}{$\begin{array}{l}\text { Reacted with LG on } \\
\text { Western blot }\end{array}$}} & & & \\
\hline & & none & all & \\
\hline
\end{tabular}

membrane (Hybond-ECL extra; Amersham, Buckingham, UK) at $90 \mathrm{~mA}$ for $45 \mathrm{~min}$ in a semi-dry transfer cell (Bio-Rad). The membrane was immersed in $1 \%$ gelatin for $1 \mathrm{~h}$ with gentle shaking. Following 3 washes with PBS for 5 min, the membrane was treated with $\mathrm{mAb}$ or polyclonal antibodies and developed with 3 to $3^{\prime}$-diaminobenzidine $\quad\left(3,3^{\prime}, 4,4^{\prime}\right.$-tetra-amino-biphenyl $)$ according to the method previously described (Yang and Mao, 1999).

\section{Trypsin Treatment on LG and Its Immunoreactivity}

For trypsin treatment, $0.6 \mu \mathrm{L}$ of trypsin $(2 \mathrm{mg} / \mathrm{mL})$ were added to $30 \mu \mathrm{g}$ of $\mathrm{LG}$ in $100 \mu \mathrm{L}$ of PBS and incubated at $37^{\circ} \mathrm{C}$ for $40 \mathrm{~min}$. The reaction was then stopped by adding SDS in a final $0.5 \%$ concentration and immediately applying SDS-PAGE containing $20 \%$ polyacrylamide gel followed by a Western blot analysis.

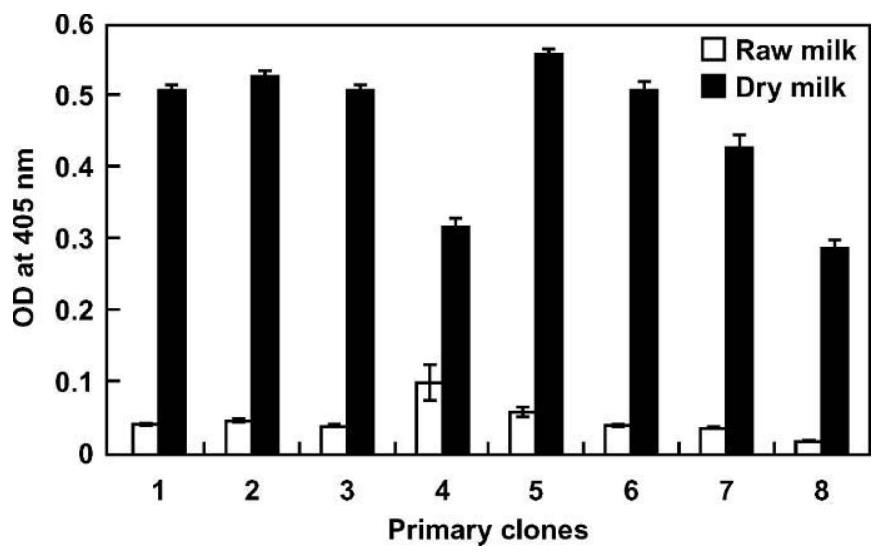

Figure 1. ELISA selection of 8 primary cultures that predominantly reacted with dry, but not raw milk. None of the culture media were diluted in the assay. Clones 1,2, 3 and 5 (1B5F2, 2F2D9, $1 \mathrm{C} 10 \mathrm{~F} 10$, and $1 \mathrm{D} 8 \mathrm{~F} 8$, respectively), which possessed the high selectivity, were subjected to monocloning by limited dilutions. $\mathrm{OD}=$ Optical density.

\section{Isotyping of $\mathrm{mAb}$}

Isotyping of each mAb was conducted according to the instruction provided by the manufacturer (Sigma,
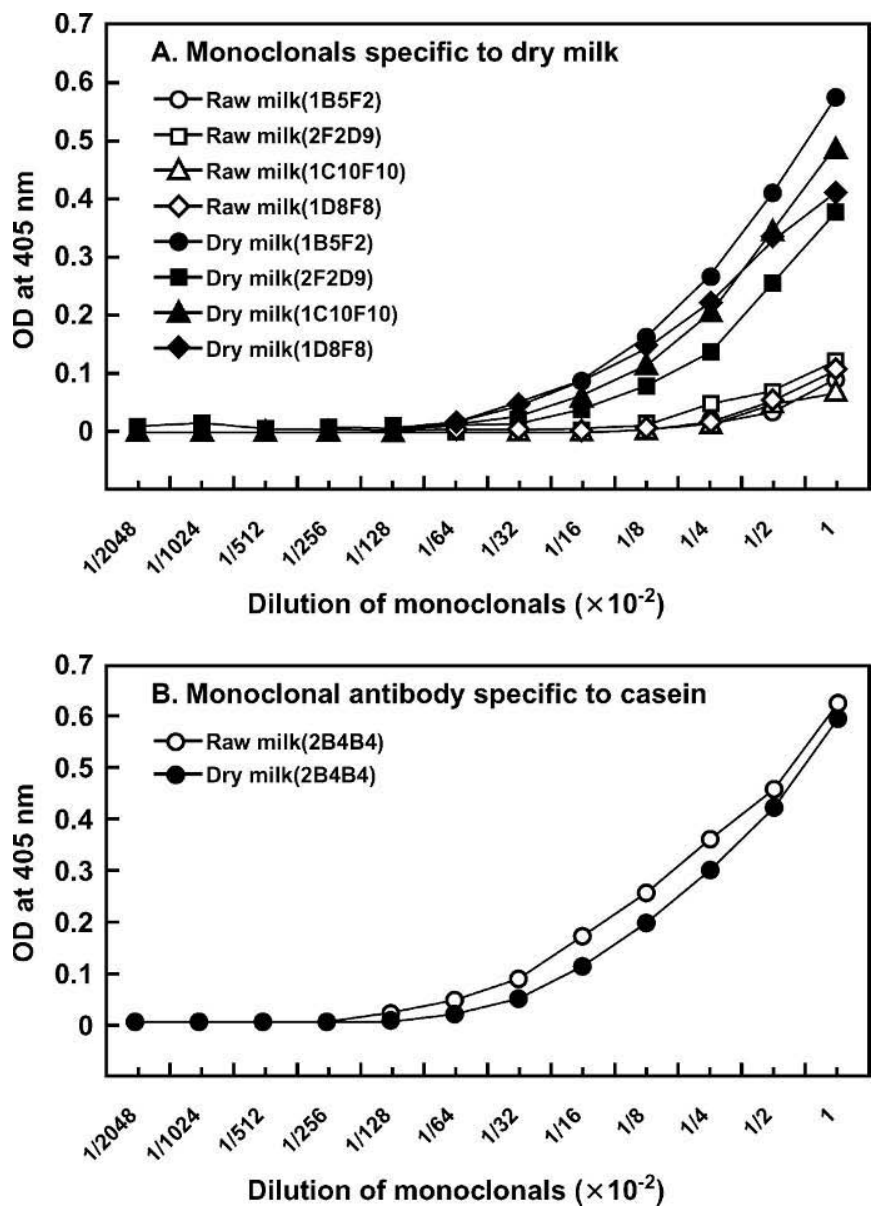

Figure 2. Dose-responsive curves of $4 \mathrm{mAb}$ (1B5F2, 2F2D9, 1C10F10, 1D8F8) specific to dry, but not raw milk (A). A typical example of mAb (2B4B4) that recognized both raw and dry milk is also shown (B). The initial dilution of each $\mathrm{mAb}$ was $1: 100$. OD = Optical density. 


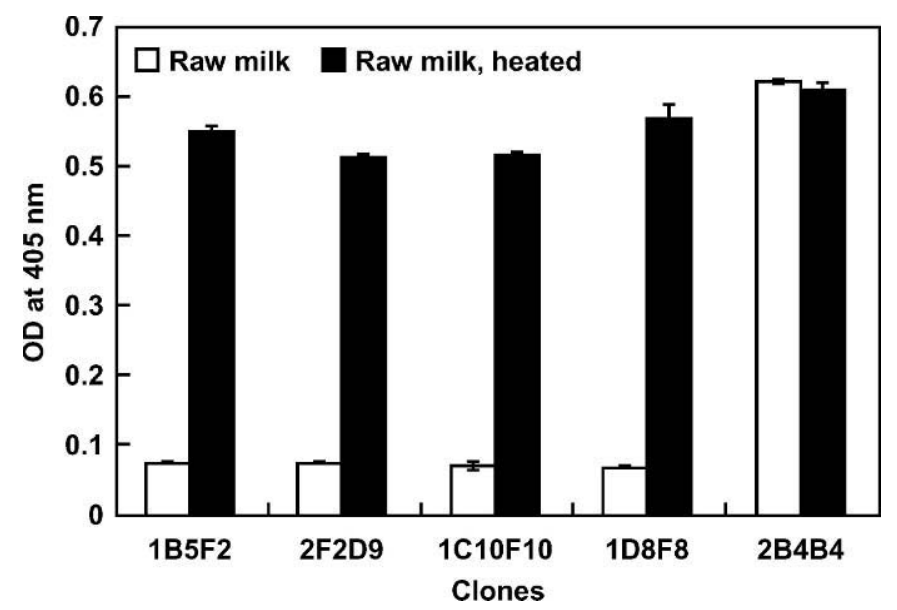

Figure 3. Effect of heat on the immunoreactivity of raw milk reacted with mAb (1B5F2, 2F2D9, 1C10F10, and 1D8F8) specific to dry milk. Clone 2B4B4 recognized both raw and dry milk. Immunoreactivity was determined using an ELISA. Data suggest a formation of "new epitope" upon the heating on raw milk $\left(95^{\circ} \mathrm{C}\right.$ for $\left.15 \mathrm{~m}\right)$. OD $=$ Optical density.

St. Louis, MO). Briefly, $1 \mu \mathrm{g}$ LG or powder milk in 50 $\mu \mathrm{L}$ of PBS was coated on an ELISA plate using the method previously established in our laboratory (Mao and Kottke, 1980; Mao et al., 1982; Yang and Mao, 1999). Following incubation with tested mAb, each monoclonal was subtyped by adding specific goat antibodies prepared against mouse IgG1, IgG2a, IgG2b, IgG3, IgM, and IgA, respectively. Finally, $50 \mu \mathrm{L}$ of HRP-labeled rabbit anti-goat Ig was used to complete the reaction as mentioned previously.

\section{RESULTS AND DISCUSSION}

It has been well established that some milk proteins are denatured during the DMLK process (mostly heat-

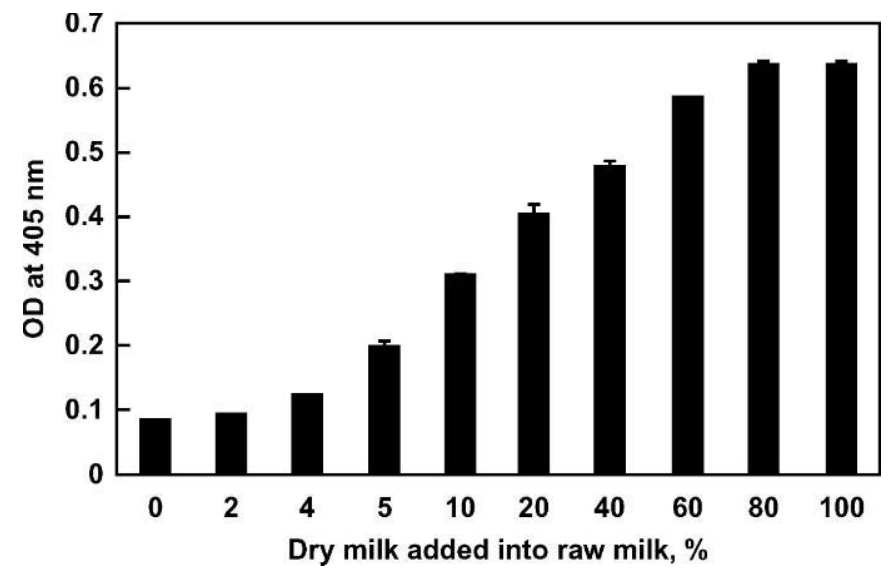

Figure 4. Immunoreactivity of raw milk when mixed with dry milk. Dry milk with various amounts was spiked into raw milk and assessed by an ELISA using mAb 1D8F8. OD = Optical density. ing is involved) (Oldfield et al., 1998). Identifying such denatured proteins might be essential in differentiating DMLK and freshly prepared raw milks. Because the structural changes are subtle, some complicated physical (Dutta et al., 1991; Pfeil, 1998; Havea et al., 2001; Anema and Li, 2003) and biochemical (Chang and Li, 2001; Valkonen et al., 2001; Bertrand-Harb et al., 2002; Jimenez-Guzman et al., 2002; Turner et al., 2002) methods have been used to monitor such changes. Previously, we have shown that mAb are extremely sensitive for probing the structural changes of human low-density lipoproteins (Mao et al., 1982) in discriminating between patients with and without coronary artery disease (Mao et al., 1983; Patton et al., 1983; Marcovina et al., 1985a, 1985b). Monoclonal antibodies prepared against human hepatic lipase can even distinguish between active and inactive forms of lipase (Mao et al., 1988). Thus, we anticipated that the mAb might allow us to detect the thermal denaturation of proteins as they occurred in heat-processed milk.

\section{Primary Screening}

As shown in Table 1, from 900 hybridomas in a primary screening, 68 reacted equally with DMLK and raw milk. Remarkably, 8 hybridomas were able to distinguish the DMLK apart from the raw milk. A typical example of the hybridomas displaying the DMLK specificity on ELISA is shown in Figure 1. In general, immunoreactivity of clones specific to DMLK was at least 8 to 10 times greater than that to raw milk. Finally, 4 monoclonals that distinctly recognized the DMLK (designated as DMLK-1, -2, -3, and -4; or 1B5F2, 1C10F10, 1D8F8, and 2F2D9, respectively) were established and used in this study (Table 1).

\section{Dose-Responsive Binding Curve of mAb to DMLK}

A representative dose-responsive curve for the immunoreactivity of each mAb specific to DMLK $(\mathrm{n}=4)$ is shown in Figure 2A. At high doses of mAb, a slight cross-reactivity with raw milk was noticed. We also tested other mAb $(n=20)$ that recognized both raw and DMLK, a typical example using mAb 2B4B4 is shown in Figure 2B. Thus, our results indicated that the $\mathrm{mAb}$ approach was novel in detecting the subtle structural changes in DMLK.

\section{Effect of Heat on the Immunoreactivity of Raw Milk}

Because heating is one of the major processes in preparation of DMLK, we hypothesized that thermal denaturation might have exposed new antigenic epi- 


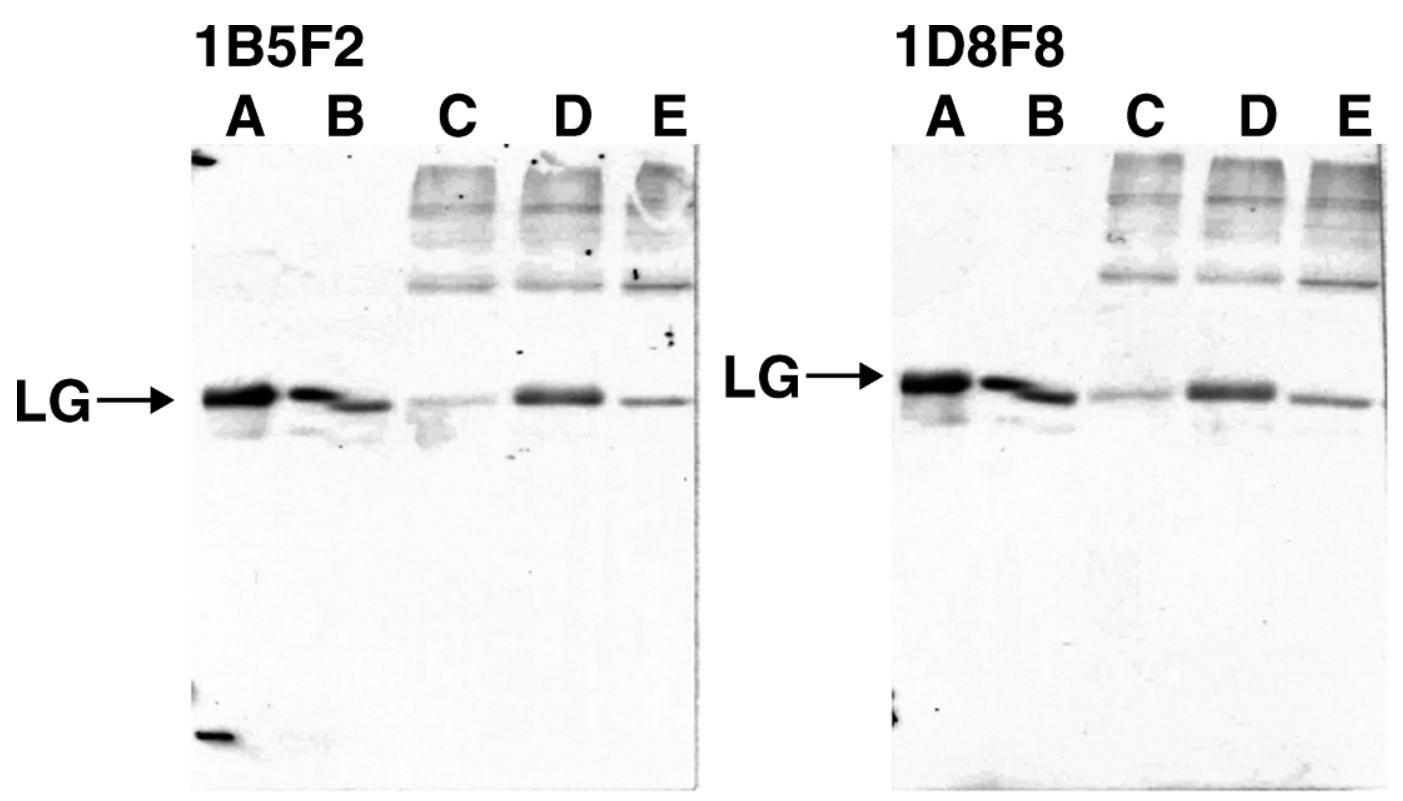

\section{F2D9}

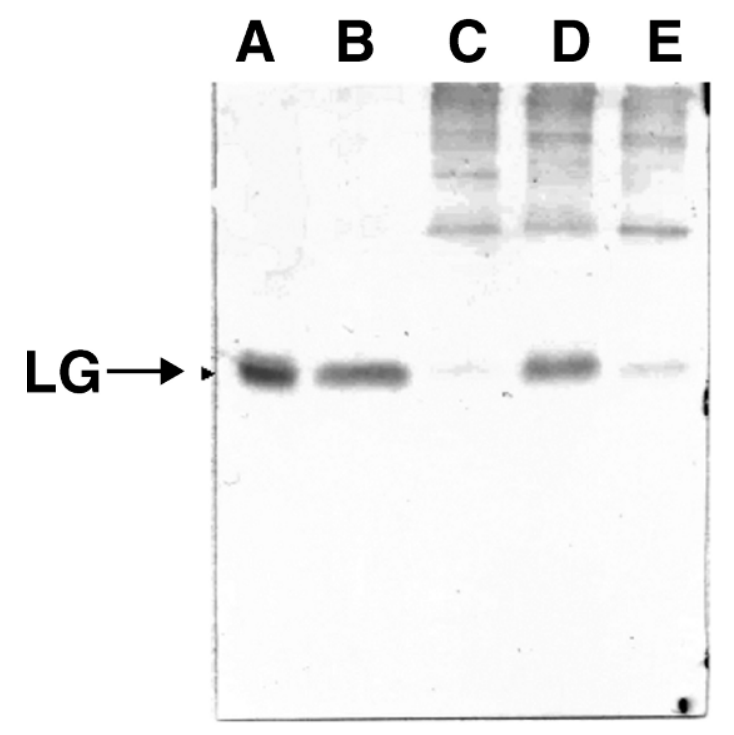

2B4B4

A B C D E

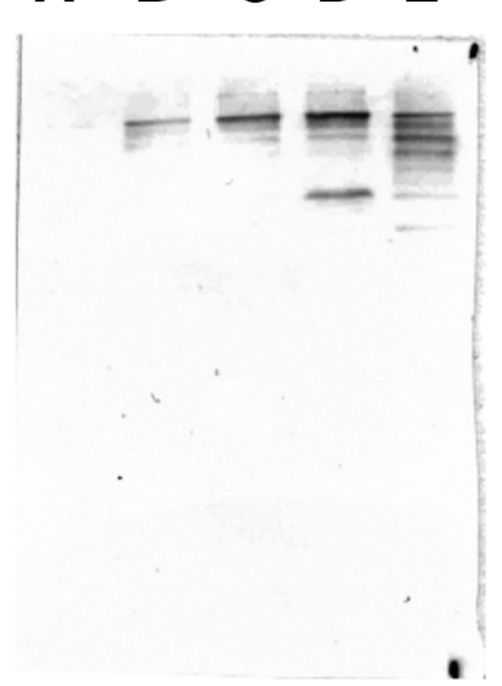

Figure 5. Characterization of mAb (1B5F2, 1D8F8, 2F2D9) specific to dry milk and a mAb (2B4B4) recognizing both dry and raw milk using a Western blot analysis. Each lane was loaded with $10 \mu \mathrm{g}$ of milk protein. Lane A: native LG; lane B: raw milk; lane C: processed "fresh" milk (from Taiwan); lane D: dry milk (from Australia); lane E: heated raw milk at $95^{\circ} \mathrm{C}$ for 15 min.

topes from the raw milk. To test this hypothesis, in the next experiment, we heated the raw milk and determined whether there were newly formed epitopes that could be probed by our specific mAb (DM-1 to DM4). Figure 3 reveals that these "new epitopes" were exposed upon the heating on raw milk, in which an increase in immunoreactivity was seen. The data suggest that these $\mathrm{mAb}$ were directed toward the heatsensitive milk proteins. It also demonstrates that the
$\mathrm{mAb}$ could detect the DMLK as low as 5\% ( $\mathrm{vol} / \mathrm{vol}$ ) spiked into the raw milk (Figure 4).

\section{Characterization of Monoclonals Specific to DMLK}

To characterize the denatured or thermal sensitive antigen(s) that recognized these 4 monoclonals, Western blot using a DMLK sample in nonheated SDSPAGE and native PAGE was conducted. All 4 of these 

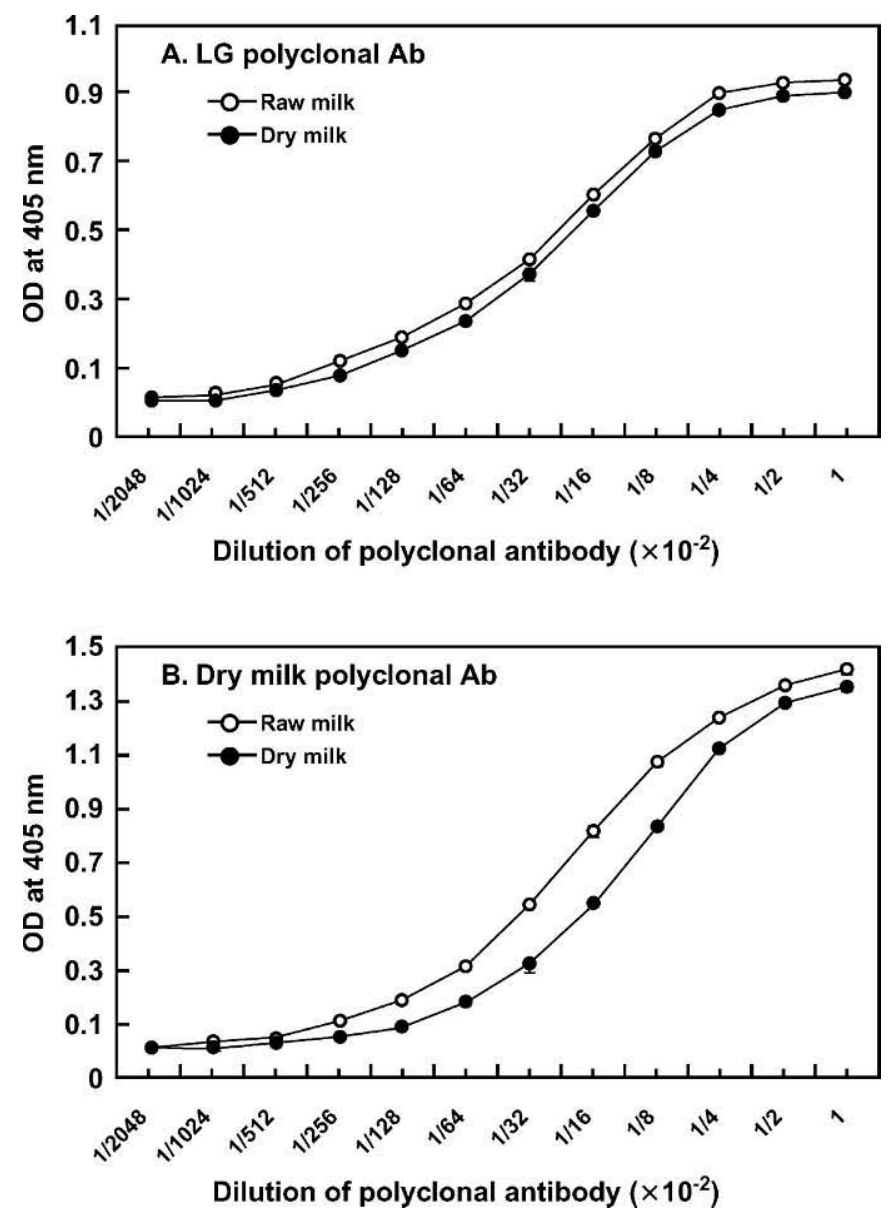

Figure 6. Dose-responsive curves for the binding of LG polyclonal antibody (A) and dry milk polyclonal antibody (B). ELISA plates were coated with raw milk $(\bigcirc)$ or dry milk $(\bullet)$. OD = Optical density.

mAb (DM-1 to DM-4) recognized LG (Figure 5A, B, and C). Simultaneously, they reacted with high molecular forms of proteins in DMLK (Lanes C, D, and E), although immunoreactivity in high molecular forms was not detected for raw milk (Lane B). We later demonstrated that these high molecular weight proteins were LG cross linked with DMLK proteins (described subsequently). Thus, the data indicated that LG is a sensitive thermal-denatured component in DMLK as judged by our mAb approach, which was initially not designed for the preparation of mAb against LG.

Conversely, none of the tested mAb $(n=20)$ that lacked specificity to DMLK could recognize LG; a typical example with such mAb, 2B4B4, is shown in Figure $5 \mathrm{D}$. Most of milk mAb reacted with casein proteins as illustrated in Western blots (Figure 5D), and they did not react with LG as judged by ELISA (data not shown). Although these mAb $(\mathrm{n}=20)$ had not been characterized fully thus far, they did not apparently recognize milk lactalbumin, albumin, and immuno- globulin. This was because any mAb initially produced against these proteins would be automatically neutralized by fetal bovine serum containing albumin and immunoglobulin. Fetal bovine serum was routinely used in the hybridoma cell culture.

\section{Lack of DMLK Specificity in Polyclonal Antibody Prepared Against LG}

An experiment was done to determine whether the polyclonal antibody prepared against DMLK or LG could also distinguish between the DMLK and raw milk, an ELISA was conducted to determine the antibody specificity. We showed that neither DMLK (panel A) nor LG (panel B) polyclonal antibody was able to detect the difference (Figure 6). Obviously, the populations of polyclonal antibodies prepared against LG or DMLK recognize the multiple epitopes that are commonly shared in both DMLK and raw milk. The finding substantiates the hypothesis that $\mathrm{mAb}$ were specific to a unique LG epitope in DMLK.

\section{Hypothetical Model of Immunochemical Property of LG in DMLK}

We demonstrated that all 4 of these randomly prepared $\mathrm{mAb}$ recognized $\mathrm{LG}$ and its denatured larger molecular form in DMLK (Figure 5). These mAb also recognized LG in raw milk to some extent on Western blot (Figure 5). But, on ELISA, these mAb were capable of differentiating DMLK and raw milk. To explain how these monoclonals effectively bound to LG in DMLK, but not to that in raw milk, we show a hypothetical model (Figure 7). First, it is probably not so surprising that the ELISA approach was feasible, because the unique mAb were initially identified by the ELISA. One of the possible mechanisms by which the mAb differentially reacted with the DMLK was that the specific LG epitope was either being masked by the polystyrene surface on ELISA plate or interacting with the other milk proteins during the immobilization of milk antigen (Figure 7A). Therefore, the mAb could not bind that specific LG epitope in raw milk. In DMLK (Figure 7B), LG was crossly linked to the other milk proteins, possibly via disulfide linkages (Figure 5). With such cross-linking, the LG epitope emerged again at the surface, making it accessible for the binding of mAb (Figure 7B). To prove that LG was crossly linked with other milk proteins in DMLK via disulfides, we treated the DMLK with a reducing reagent (mercaptoethanol) to eliminate the disulfide linkages (if any). Under this condition, the mAb (DMLK 1 to 4) did not react with any cross-linking forms of LG as demonstrated on a Western blot (Figure 8). Furthermore, 
A. Dry milk-specific mAb vs. raw milk

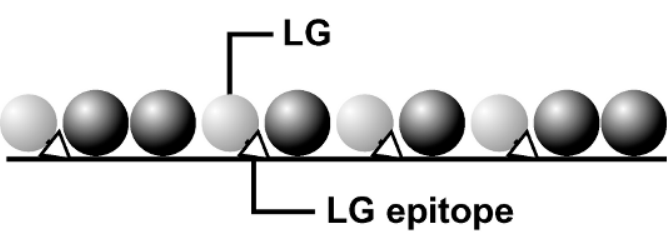

C. LG polyclonal Ab vs. raw milk

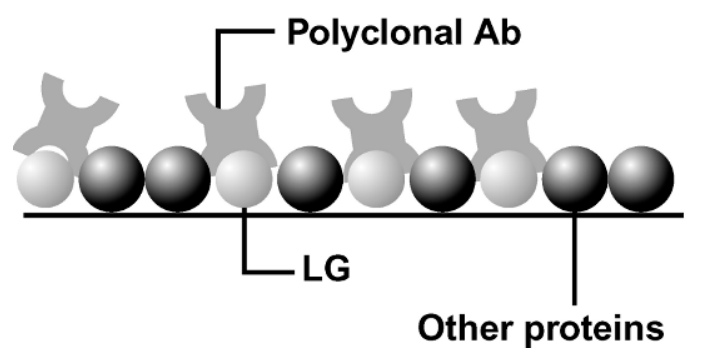

\section{B. Dry milk-specific mAb vs. dry milk}

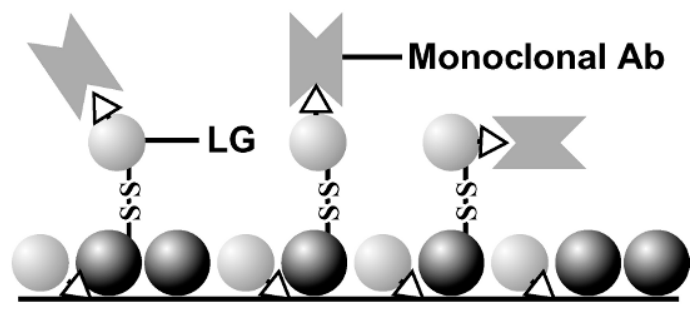

D. LG polyclonal Ab vs. dry milk

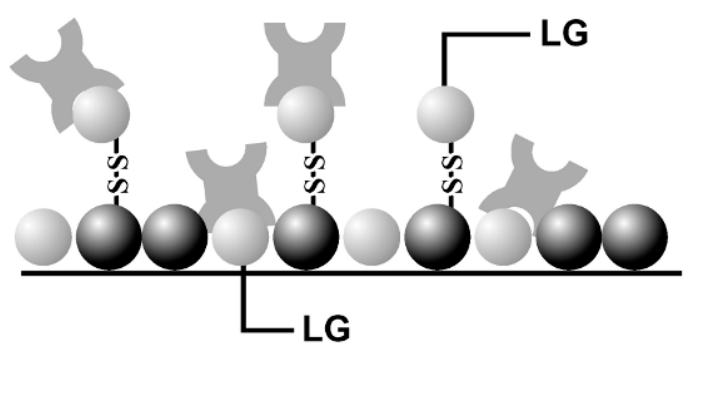

Figure 7. A hypothetical model explaining the mechanism by which dry milk specific mAb recognizes the epitope of dry milk. (A) LG specific epitope is masked by the polystyrene surface on the ELISA plate. Therefore, mAb (DM 1 to 4) cannot bind to the specific LG epitope in raw milk. (B) LG conjugates with other milk protein moiety and exposes the epitope in heat processed dry milk and therefore facilitates mAb to bind LG specific epitope. (C) LG polyclonal antibodies recognize many other LG epitopes in raw milk. (D) LG polyclonal antibodies recognize many LG epitopes regardless the disulfide cross-linkings. Notably, we still cannot rule out that the possible conformational change of this LG epitope upon the heating is responsible for the recognition by the mAb.

LG polyclonal antibodies, which did not recognize the unique LG epitope, would bind both raw (Figure 7C) and DMLK (Figure 7D) as mentioned previously.

We concluded that cross-linking of LG with other milk proteins may play an essential role in our ELISA system by providing the additional epitope for $\mathrm{mAb}$ binding. However, we still cannot rule out that the possible conformational change of this LG epitope upon heating is responsible for the recognition by the $\mathrm{mAb}$. As to the specific epitope that interacts with the plate interface or $\mathrm{mAb}$, we have yet to identify such epitope at the present time. However, our preliminary data show that this epitope of LG was somewhat sensitive to trypsin cleavage. A typical example of the immunoreactivity affected by trypsin treatment on Western blot is depicted in Figure 9. Subtyping of IgG class revealed that all $\mathrm{mAb}$ reported in this study were IgG1 without exceptions (Table 1). Further antigenic mapping of LG is now in progress, which may provide the insight of the surface property of LG and its interaction with mAb.
With respect to the possible mechanism involved in the cross-linking, one can rationalize it as follows. Lactoglobulin is a protein that consists of 162 amino acids containing 5 cysteines at residues $66,106,119$, 121 , and 160 . There are 2 proposed cross-linking disulfide bonds at position Cys 66 to 160 and Cys 106 to 119 (Papiz et al., 1986; Cho et al., 1994; Cho et al., 2003). Activation of free Cys 121 by thermal treatment in milk has been thought to induce the disulfide bond formation between LG (dimerization) and K-casein (Doi et al., 1985; Kitabatake et al., 2001; Henry et al., 2002). Our Western blot (Figure 5) showed that LG monoclonals reacted with both LG and LG conjugates (large molecular forms), and mercaptoethanol treatment reversed the immunoreactivity of LG conjugates (Figure 8). The result supports the notion that LG crossly links with other proteins in DMLK (Figure 7). In the present study, at least 3 milk proteins were found to be involved in such linkages (Figure 5), although we have not identified these proteins yet. Nevertheless, the Western blot technique recognizing the 

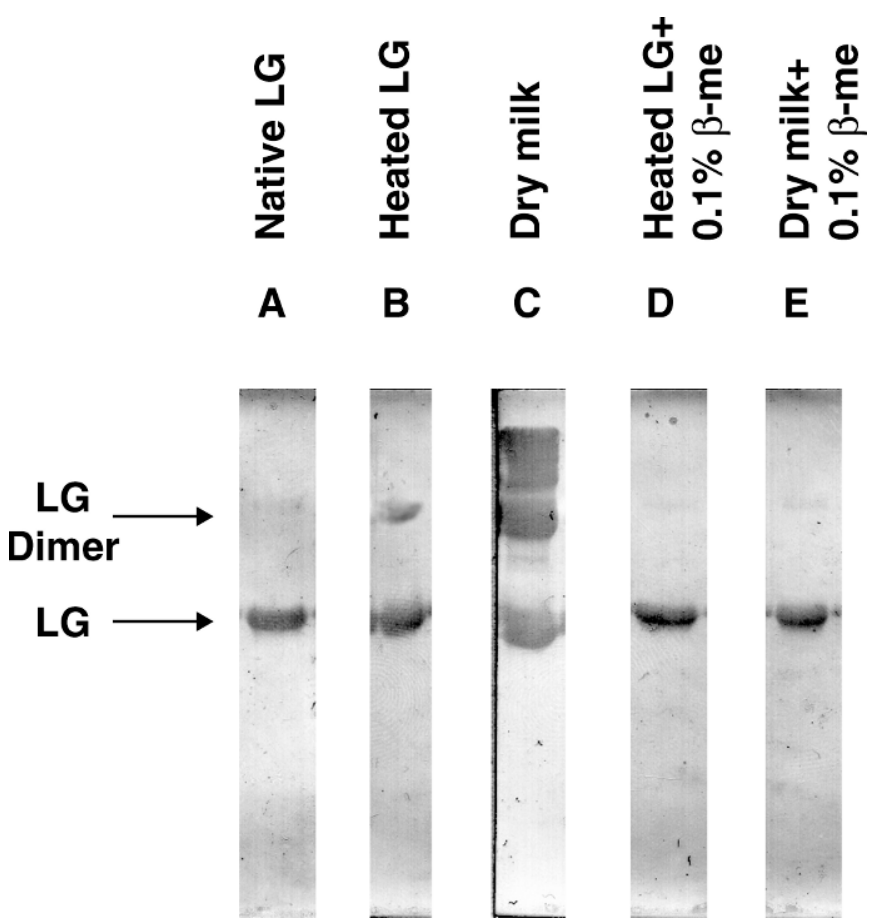

Figure 8. Western blot analysis on LG and dry milk treated with reducing reagent. About $10 \mu \mathrm{g}$ of each respective protein were load on $15 \%$ SDS-PAGE. A final concentration of $0.1 \% \beta$-mercaptoethanol was used as a reducing reagent. species crossly linked by LG may help us to further delineate the cross-linking between LG and milk proteins.

Finally, as to the effect of heat on the other food proteins, Carbonaro et al. (1999) have shown that the proteins extracted from cooked common beans are more resistant to proteolysis (because of the formation of protein aggregation) than are raw beans. The iron absorption from heme in beef exposed to prolonged heating was substantially reduced in humans (Martinez-Torres et al., 1986). In egg-allergic patients, heat treatment and disulfide blockage dramatically decrease the antigenicity of ovotransferrin and ovomucoid, but not ovalbumin (Mine and Zhang, 2002). Because milk LG can be directly absorbed into the gastrointenstinal tract of human infants (Kuitunen et al., 1994a, 1994b; Sorva et al., 1994), whether the crosslinking formation of over-heated milk reduces absorption of amino acid supplements remains a worthy subject of investigation.

\section{ACKNOWLEDGMENT}

This work was supported by grants $90-2313-\mathrm{B}-009$ 001 and 91-2313-B-009-001 from the National Science Council of Taiwan.

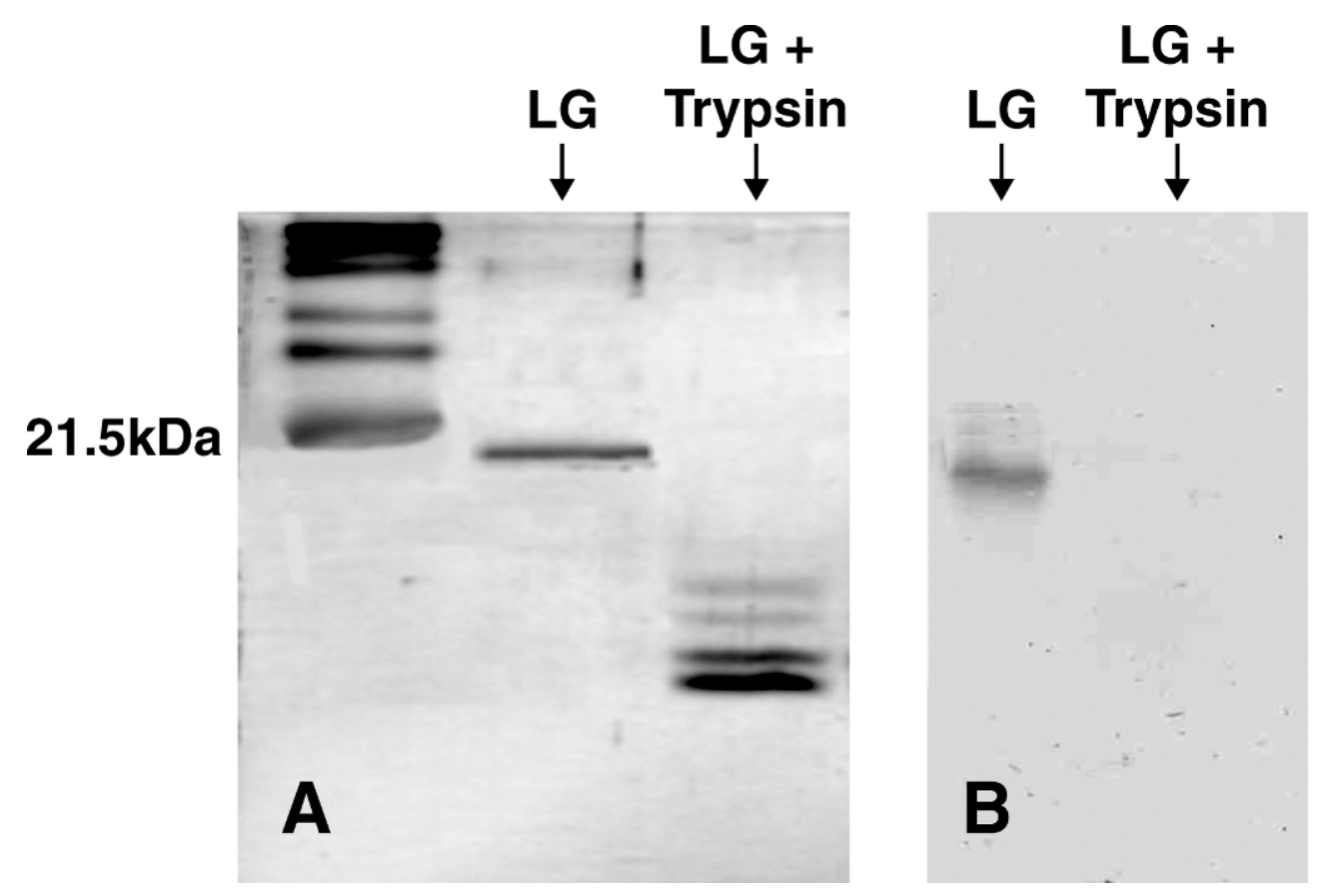

Figure 9. Effect of trypsin cleavage on the immunoreactivity of LG using dry milk specific mAb. A typical example is shown herein using clone 1D8F8. Left- Coomassie blue staining on 20\% SDS-PAGE. Right- Western blot analysis. 


\section{REFERENCES}

Anema, S. G., and Y. Li. 2003. Association of denatured whey proteins with casein micelles in heated reconstituted skim milk and its effect on casein micelle size. J. Dairy Res. 70:73-83.

Bertrand-Harb, C., A. Baday, M. Dalgalarrondo, J. M. Chobert, and T. Haertle. 2002. Thermal modifications of structure and codenaturation of alpha-lactalbumin and beta-lactoglobulin induce changes of solubility and susceptibility to proteases. Nahrung 46:283-289.

Carbonaro, M., S. Nicoli, and G. Musci. 1999. Heat-induced aggregation of Phaseolus vulgaris L. proteins: An electron spin resonance study. J. Agric. Food Chem. 47:2188-2192.

Chang, J. Y., and L. Li. 2001. The structure of denatured alphalactalbumin elucidated by the technique of disulfide scrambling: Fractionation of conformational isomers of alpha-lactalbumin. J. Biol. Chem. 276:9705-9712.

Cho, Y., W. Gu, S. Watkins, S. P. Lee, T. R. Kim, J. W. Brady, and C. A. Batt. 1994. Thermostable variants of bovine betalactoglobulin. Protein Eng. 7:263-270.

Cho, Y., H. Singh, and L. K. Creamer. 2003. Heat-induced interactions of beta-lactoglobulin A and kappa-casein B in a model system. J. Dairy Res. 70:61-71.

Clement, G., D. Boquet, Y. Frobert, H. Bernard, L. Negroni, J. M. Chatel, K. Adel-Patient, C. Creminon, J. M. Wal, and J. Grassi. 2002. Epitopic characterization of native bovine beta-lactoglobulin. J. Immunol. Methods 266:67-78.

Doi, H., M. Hiramatsu, F. Ibuki, and M. Kanamori. 1985. Gelation of the heat-induced complex between kappa-casein and alphalactalbumin. J. Nutr. Sci. Vitaminol. (Tokyo) 31:77-87.

Dutta, P. K., K. Hammons, B. Willibey, and M. A. Haney. 1991. Analysis of protein denaturation by high-performance continuous differential viscometry. J. Chromatogr. 536:113-121.

Havea, P., H. Singh, and L. K. Creamer. 2001. Characterization of heat-induced aggregates of beta-lactoglobulin, alpha-lactalbumin and bovine serum albumin in a whey protein concentrate environment. J. Dairy Res. 68:483-497.

Henry, G., D. Molle, F. Morgan, J. Fauquant, and S. Bouhallab. 2002. Heat-induced covalent complex between casein micelles and beta-lactoglobulin from goat's milk: Identification of an involved disulfide bond. J. Agric. Food Chem. 501:185-191.

Huang, G. S., S. P. Wang, W. T. Chang, T. J. Sun, S. C. Wang, R. $\mathrm{Chu}$, and S. J. T. Mao. 1999. Intracellular processing generated MDA-lys epitope in foam cells. Life Sci. 65:285-296.

Jimenez-Guzman, J., A. E. Cruz-Guerrero, G. Rodriguez-Serrano, A. Lopez-Munguia, L. Gomez-Ruiz, and M. Garcia-Garibay. 2002. Enhancement of lactase activity in milk by reactive sulfhydryl groups induced by heat treatment. J. Dairy Sci. 85:2497-2502.

Kitabatake, N., R. Wada, and Y. Fujita. 2001. Reversible conformational change in beta-lactoglobulin A modified with N-ethylmaleimide and resistance to molecular aggregation on heating. J. Agric. Food Chem. 49:4011-4018.

Kobayashi, K., A. Hirano, A. Ohta, T. Yoshida, K. Takahashi, and M. Hattori. 2001. Reduced immunogenicity of beta-lactoglobulin by conjugation with carboxymethyl dextran differing in molecular weight. J. Agric. Food Chem. 49:823-831.

Kuitunen, M., E. Savilahti, and A. Sarnesto. 1994a. Human alphalactalbumin and bovine beta-lactoglobulin absorption in infants. Allergy 49:354-360.

Kuitunen, M., E. Savilahti, and A. Sarnesto. 1994b. Human alphalactalbumin and bovine beta-lactoglobulin absorption in premature infants. Pediatr. Res. 35:344-347.

Mao, S. J. T., R. E. Kazmar, J. C. Silverfield, M. C. Alley, K. Kluge, and C. G. Fathman. 1982. Immunochemical properties of human low density lipoproteins as explored by monoclonal antibodies. Binding characteristics distinct from those of conventional serum antibodies. Biochim. Biophys. Acta 713:365-374.

Mao, S. J. T., and B. A. Kottke. 1980. Tween-20 increases the immunoreactivity of apolipoprotein A-I in plasma. Biochim. Biophys. Acta 620:447-453.
Mao, S. J. T., J. G. Patton, J. J. Badimon, B. A. Kottke, M. C. Alley, and A. D. Cardin. 1983. Monoclonal antibodies to human plasma low-density lipoproteins. I. Enhanced binding of 125I-labeled low-density lipoproteins by combined use of two monoclonal antibodies. Clin. Chem. 29:1890-1897.

Mao, S. J. T., A. E. Rechtin, and R. L. Jackson. 1988. Monoclonal antibodies that distinguish between active and inactive forms of human postheparin plasma hepatic triglyceride lipase. J. Lipid Res. 29:1023-1029.

Mao, S. J. T., A. E. Rechtin, J. L. Krstenansky, and R. L. Jackson. 1990. Characterization of a monoclonal antibody specific to the amino terminus of the alpha-chain of human fibrin. Thromb. Haemost. 63:445-448.

Marcovina, S., D. France, R. A. Phillips, and S. J. T. Mao. 1985a. Monoclonal antibodies can precipitate low-density lipoprotein. I. Characterization and use in determining apolipoprotein B. Clin. Chem. 31:1654-1658.

Marcovina, S., B. A. Kottke, and S. J. T. Mao. 1985b. Monoclonal antibodies can precipitate low-density lipoprotein. II. Radioimmunoassays with single and combined monoclonal antibodies for determining apolipoprotein B in serum of patients with coronary artery disease. Clin. Chem. 31:1659-1663.

Martinez-Torres, C., I. Leets, P. Taylor, J. Ramirez, M. del Valle Camacho, and M. Layrisse. 1986. Heme, ferritin and vegetable iron absorption in humans from meals denatured of heme iron during the cooking of beef. J. Nutr. 116:1720-1725.

Mine Y., and J. W. Zhang. 2002. Comparative studies on antigenicity and allergenicity of native and denatured egg white proteins. J. Agric. Food Chem. 509:2679-2683.

Morgan, F., A. Venien, S. Bouhallab, D. Molle, J. Leonil, G. Peltre, and D. Levieux. 1999. Modification of bovine beta-lactoglobulin by glycation in a powdered state or in an aqueous solution: Immunochemical characterization. J. Agric. Food Chem. 47:4543-4548.

Oldfield, D. J., H. Singh, M. W. Taylor, and K. N. Pearce. 1998. Kinetics of denaturation and aggregation of whey protein in skim milk heated in an ultra-high temperature (UHT) plant. Int. Dairy J. 8:311-318.

Papiz, M. Z., L. Sawyer, E. E. Eliopoulos, A. C. North, J. B. Findlay, R. Sivaprasadarao, T. A. Jones, M. E. Newcomer, and P. J. Kraulis. 1986. The structure of beta-lactoglobulin and its similarity to plasma retinol-binding protein. Nature 324:383-385.

Patton, J. G., J. J. Badimon, and S. J. T. Mao. 1983. Monoclonal antibodies to human plasma low-density lipoproteins. II. Evaluation for use in radioimmunoassay for apolipoprotein B in patients with coronary artery disease. Clin. Chem. 29:1898-1903.

Pfeil, W. 1998. Is the molten globule a third thermodynamic state of protein? The example of alpha-lactalbumin. Proteins 30:43-48.

Recio, I., and C. Olieman. 1996. Determination of denatured serum proteins in the casein fraction of heat-treated milk by capillary zone electrophoresis. Electrophoresis 17:1228-1233.

Relkin, P. 1996. Thermal unfolding of beta-lactoglobulin, alphalactalbumin, and bovine serum albumin. A thermodynamic approach. Crit. Rev. Food Sci. Nutr. 36:565-601.

Restani, P., A. Gaiaschi, A. Plebani, B. Beretta, G. Cavagni, A. Fiocchi, C. Poiesi, T. Velona, A. G. Ugazio, and C. L. Galli. 1999. Cross-reactivity between milk proteins from different animal species. Clin. Exp. Allergy 29:997-1004.

Sanchez, L., M. D. Perez, P. Puyol, M. Calvo, and G. Brett. 2002. Determination of vegetal proteins in milk powder by enzymelinked immunosorbent assay: Interlaboratory study. J. AOAC Int. 85:1390-1397.

Selo, I., C. Creminon, J. Grassi, and J. Y. Couraud. 2002. Antiallergen antibodies can be neutralized by antibodies obtained against a peptide complementary to the allergen: towards a new peptide therapy for allergy. Immunol. Lett. 80:133-138.

Sorva, R., S. Makinen-Kiljunen, and K. Juntunen-Backman. 1994. Beta-lactoglobulin secretion in human milk varies widely after cow's milk ingestion in mothers of infants with cow's milk allergy. J. Allergy Clin. Immunol. 93:787-792. 
Steffensen, C. L., H. J. Andersen, and J. H. Nielsen. 2002. Aldehydeinduced xanthine oxidase activity in raw milk. J. Agric. Food Chem. 50:7392-7395.

Tsonev, L. I., and A. G. Hirsh. 2000. Fluorescence ratio intrinsic basis states analysis: A novel approach to monitor and analyze protein unfolding by fluorescence. J. Biochem. Biophys. Methods 45:1-21.

Turner, J. A., L. R. Sivasundaram, M. A. Ottenhof, I. A. Farhat, R. S. Linforth, and A. J. Taylor. 2002. Monitoring chemical and physical changes during thermal flavor generation. J. Agric. Food Chem. 50:5406-5411.
Valkonen, K. H., N. Marttinen, and T. Alatossava. 2001. Electrophoretic methods for fractionation of native and heat-denatured bovine beta-lactoglobulin. Bioseparation 10:145-152.

Venien, A., D. Levieux, C. Astier, L. Briand, J. M. Chobert, and T. Haertle. 1997. Production and epitopic characterization of monoclonal antibodies against bovine beta-lactoglobulin. J. Dairy Sci. 80:1977-1987.

Yang, S. J., and S. J. T. Mao. 1999. A simple HPLC purification procedure for porcine plasma haptoglobin. J. Chromatagr. B 731:395-402. 